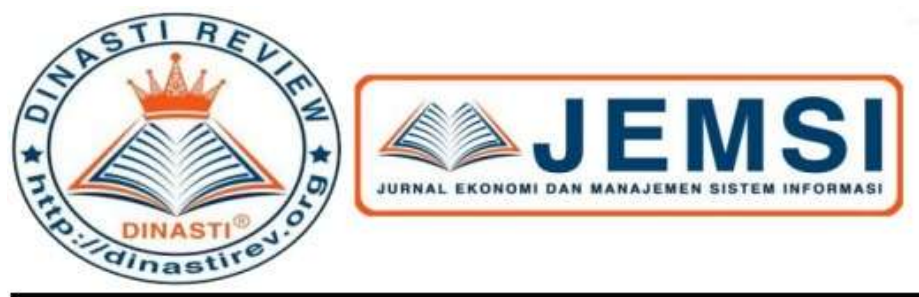

+62 878-9658-6407

087896586407 ()

https://dinastirev.org/JEMSI (7)

editor@dinastirev.org@.

\title{
STRATEGIC MANAGEMENT EFE-IFE MATRIX, SWOT ANALYSIS, COMPETITIVE PROFIL MATRIX (CPM) DAN BCG MATRIX PADA PT YAMAHA
}

\section{Samrotul Janiah \\ Universitas Mercu Buana, Jakarta, Indonesia}

\begin{abstract}
ARTICLE INFORMATION
Received: 23 Desember 2019

Revised: 28 Desember 2019

Issued: 31 Desember 2019

(filled in by Editor)
\end{abstract}

Corresponding author: first author

E-mail:

sjaniah19@gmail.com

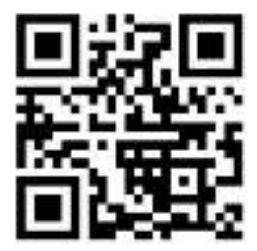

DOI:10.31933/JEMSI
Abstrak: Tujuan penulisan ini adalah untuk menganalisis Strategic Management yang dilakukan pada PT YAMAHA. Adapun permasalahan yang dianalisis oleh penulis akan difokuskan pada EFE-IFE Matrix, SWOT Analysis, Competitive Profil Matrix $(C P M)$ dan $B C G$ Matrix. Untuk menentukan strategi utama bisnis di industri otomotif PT YAMAHA selalu merancang strategi pemasaran untuk meningkatkan pembelian konsumen, dapat bersaing dengan pabrikan sepeda motor lainnya dalam hal menjangkau pasar, kualitas hasil produksi, dalam rangka memenuhi kepuasan konsumen. Penulisan ini dilatar belakangi PT YAMAHA adalah sebagai salah satu perusahaan otomotif yang terus berupaya untuk membuat produk berbeda kelas sehingga bisa masuk ke dalam pangsa pasar yang berbeda-beda. Sehingga diperlukannya suatu analisis untuk menentukan strategi utama bisnis yang akurat, yang dapat memusatkan perhatian posisi di bisnis tersebut, mengetahui sasaran atau target yang akan dicapai, bagaimana mencapainya serta tindakan apa yang perlu dilakukan agar dapat memaksimalkan kekuatan dan merebut peluang. Perencanaan bisnis yang baik merupakan alat yang sangat berguna untuk menjalankan bisnis secara efektif dan efisien. Hasil penelitian ini didapatkan peluang yang terbesar, Ancaman yang terkecil, Kekuatan yang tertinggi dan kelemahan yang terendah. Dan kesimpulannya berupa Program yang akan dilaksanakan dari alternatif strategi yang telah ditentukan mengacu pada bauran pemasaran jasa (marketing mix) yang merupakan kombinasi variabel atau kegiatan inti dari salah satu sistem pemasaran dalam pengembangan perusahaan, variabel tersebut dapat dikendalikan oleh perusahaan untuk mempengaruhi tanggapan konsumen dalam pasar sasarannya sehingga bisa diimplementasikan sebagai strategi untuk meningkatkan pendapatan PT YAMAHA. 


\begin{tabular}{|l|l|}
\hline & Kata Kunci: Strategic Management, EFE-IFE Matrix, \\
& SWOT Analysis, Competitive Profil Matrix, BCG \\
Matrix
\end{tabular}

\section{PENDAHULUAN}

Yamaha ingin menjadi perusahaan distributor motor, produk dan jasa pendukungnya yang memiliki jaringan pemasaran terbesar di Indonesia, hal ini terbukti Yamaha telah mampu menjalani strategi vertical integration di Indonesia yaitu strategi dimana Yamaha telah mampu membuat suku cadang serta merakit motor sendiri sehingga dapat menekan biaya import. Mengembangkan system infrastruktur, informasi teknologi serta sumber daya fisik yang tepat guna dan terintegrasi dengan departemen terkait, sesuai dengan standar yang berlaku. Melakukan terobosan dan analisa untuk pengembangan bisnis dengan membentuk jaringan-jaringan (penjualan, perawatan, dan suku cadang) baru di seluruh Indonesia.

Mengembangkan dan menempatkan karyawan sesuai dengan tuntutan kompetensi Jabatan sehingga karyawan memiliki kapasitas serta dapat menjalankan tugas-tugas dan tanggung jawabnya dengan baik. Identifikasi Peluang dan Tantangan Eksternal Perusahaan

1. Peluang :

- Perubahan gaya hidup konsumen.

- Perubahan teknologi.

- Populasi penduduk terbesar ketiga di Asia.

- Kenaikan tingkat permintaan kendaraan motor beroda dua.

- Kenaikan tingkat kemacetan lalu lintas di kota-kota besar.

2. Tantangan :

- Keterbatasan minyak bahan bakar Indonesia dan Dunia.

- Persaingan pasar sepeda motor nasional.

- Maraknya produk motor asal China yang masuk ke Indonesia.

- Kebijakan pemerintah mengenai pembatasan BBM bersubsidi (premium).

- Kebijakan pemerintah terhadap pengurangan jumlah kendaraan roda dua mengurangi lalu lintas (meski masih sekedar wacana).

\section{KAJIAN PUSTAKA}

\section{Matriks EFE-IFE}

EFE Matriks (External Factor Evaluation) merupakan strategi untuk merangkum dan mengevaluasi informasi ekonomi, sosial, budaya, demografi, lingkungan, politik, pemerintah, hukum, teknologi dan persaingan yang di hadapi oleh perusahaan. Sedangkan IFE Matriks (internal Factor Evaluation) adalah matrix perusahaan yang menganalisa dua variabel yaitu strength (kekuatan), apa saja yang dimiliki oleh sebuah perusahaan dan weakness (kelemahan) yang ada dalam perusahaan itu sendiri.

\section{SWOT Analysis}

Adalah identifikasi berbagai faktor secara sistematis untuk merumuskan strategi perusahaan. Analisis ini didasarkan pada logika yang dapat memaksimalkan kekuatan (strength) dan peluang (Opportunity), namun secara bersamaan dapat meminimalkan kelemahan (weaknesses) dan ancaman (Threat) (Freddy Rangkuti, 2001). Hafianto Bambang tahun 2009 menyatakan dalam Analisis SWOT akan melibatkan penentuan tujuan yang 
spesifik dari spekulasi bisnis atau proyek dan mengidentifikasi faktor internal dan eksternal yang mendukung dan yang tidak dalam mencapai tujuan tersebut.

1. Strength; faktor internal yang mendukung perusahaan dalam mencapai tujuannya. Faktor pendukung dapat berupa sumber daya, keahlian, atau kelebihan lain yang mungkin diperoleh berkat sumber keuangan, citra, keunggulan di pasar, serta hubungan baik antara buyer dengan supplier.

2. Weakness; faktor internal yang menghambat perusahaan dalam mencapai tujuannya. Faktor penghambat dapat berupa fasilitas yang tidak lengkap, kurangnya sumber keuangan, kemampuan mengelola, keahlian pemasaran dan citra perusahaan.

3. Opportunity; faktor eksternal yang mendukung perusahaan dalam mencapai tujuannya. Faktor eksternal yang mendukung dalam pencapaian tujuan dapat berupa perubahan kebijakan, perubahan persaingan, perubahan teknologi dan perkembangan hubungan supplier dan buyer.

4. Threat; faktor eksternal yang menghambat perusahaan dalam mencapai tujuannya. Faktor eksternal yang menghambat perusahaan dapat berupa masuknya pesaing baru, pertumbuhan pasar yang lambat, meningkatnya bargaining power daripada supplier dan buyer utama, perubahan teknologi serta kebijakan baru.

\section{Competitive Profil Matrix (CPM) atau Matriks Profil Kompetitif}

Definisi Competitive Profile Matrix adalah sebuah alat manajemen strategis yang penting untuk mengidentifikasi kekuatan dan kelemahan pesaing utama dalam hubungannya dengan posisi strategis perusahaan. Competitive Profile Matrix disusun dengan cara membandingkan key success factor dan critical success factor yang dimiliki olrh sebuah perusahaan dengan para pesaingnya. Dari sini dapat diketahui seberapa kuatnya posisi perusahaan dibandingkan pesaing.

\section{BCG Matrix atau Matriks BCG}

Adalah alat analisis bisnis yang digunakan untuk membantu perusahaan dalam mempertimbangkan peluang pertumbuhan dengan perencanaan strategis jangka panjang dan meninjau portofolio produk perusahaan tersebut agar dapat mengambil keputusan untuk berinvestasi, mengembangkan atau menghentikan produknya.

Matrik BCG ini juga membantu perusahaan dalam menentukan pengalokasian sumber daya dan sebagai alat analisis dalam pemasaran merek, manajemen produk, manajemen strategis dan analisis Portofolio. Matriks BCG dikembangkan oleh Bruce Henderson pada tahun 1970-an. Bruce Henderson juga merupakan pendiri Boston Consulting Group (BCG) yaitu sebuah perusahaan konsultan manajemen global yang terkemuka yang pernah menduduki peringkat ketiga perusahaan terbaik untuk bekerja versi Forbes pada tahun 2014 . Karena Matriks ini dikembangkan oleh pendiri Boston Consulting Group (BCG) maka matriks ini dinamakan dengan Matrik BCG yang singkatan dari Boston Consulting Group. Matriks BCG ini juga berkaitan erat dengan siklus hidup produk (Products life cycle) sehingga sering disebut juga dengan Product Portfolio Matrix (Matriks Portofolio Produk). Nama- nama lain Matriks BCG diantaranya adalah BCG Growth-Share Matrix (Matriks Pertumbuhan dan Pangsa Pasar BCG), Boston Box dan Portfolio Diagram (Diagram Portofolio). 


\section{METODE PENELITIAN}

Jenis penulisan deskriptif bertujuan membuat deskripsi secara sistematis, faktual, dan akurat tentang fakta-fakta dan sifat-sifat populasi atau objek tertentu. Penulisan deskriptif, yaitu penulisan yang berusaha untuk menuturkan pemecahan masalah yang ada sekarang berdasarkan data-data, menyajikan data, menganilisis dan menginterpretasi. Dalam hal ini penulis menggambarkan suatu gejala yang sedang terjadi berdasarkan indikator-indikator tertentu dari konseptual yang dioperasionalkan, dan tidak bermaksud menjelaskan suatu hubungan antarvariabel. Data yang diperoleh bersumber dari website perusahaan.

Analisis data yang digunakan dalam penulisan ini adalah teknik analisi model interaktif yang didalamnya ada tiga komponen analisis diantaranya reduksi data, penyajian data, dan penarikan simpulan yang dilakukan serempak dengan bentuk interaktif yang proses pengumpulan data sebagai siklus. Komponen analisis tersebut dilaksanakan secara terpadu selama dan sesudah pengumpulan data.

\section{HASIL DAN PEMBAHASAN}

External Factor Evaluation (EFE) Matriks Perusahaan

\begin{tabular}{|c|c|c|c|c|}
\hline & Faltor falstor Erternal Utama & Bobot & Kating & Skor \\
\hline \multicolumn{5}{|c|}{ Opportunities } \\
\hline 1 & 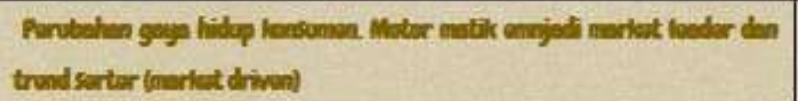 & 0,10 & 3 & 0,30 \\
\hline 2 & Purubuhan talonologi & 0,11 & 4 & 0,44 \\
\hline 3 & 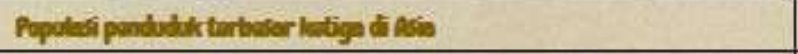 & 0,10 & 1 & 0,10 \\
\hline 4. & Kanalen tinglott purninten kenderaen bornotur roda dus & 0,12 & 3 & 0,36 \\
\hline \multirow[t]{2}{*}{5} & 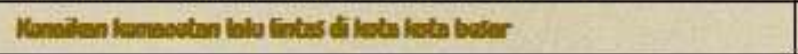 & 0,10 & 3 & 0,30 \\
\hline & Threat & & & \\
\hline t & 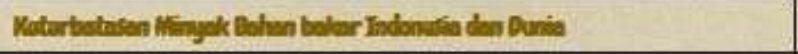 & 0,11 & 2 & 0,22 \\
\hline & Pursaingen Fuser slepoda motar nasionel & 0,14 & 4 & 0,86 \\
\hline & 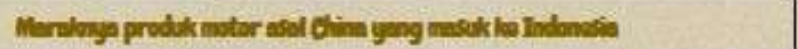 & 0,09 & 3 & 0,27 \\
\hline & 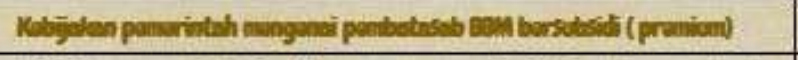 & 0,08 & 2 & 0,16 \\
\hline & 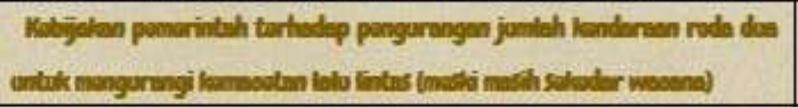 & 0,05 & 1 & 0,05 \\
\hline & TOTAL & 1,00 & & 2,76 \\
\hline
\end{tabular}

Gambar 1. Factor Exteral Utama

\section{Internal Factor Evaluation (IFE) Matrik Perusahaan}

Identifikasi Kelemahan dan Kekuatan Internal Perusahaan

1. Kekuatan

a. Memiliki brand management yang baik melalui brand ambassador yang representative terhadap produknya.

b. Memiliki consummer dan community management melalui promosi yang intensdan intim.

c. Menjalani strategi vertical integration operasi pembuatan suku cadang, perakitan motor dan pemasaran di Indonesia.

2. Kelemahan

a. Product line yang terbatas, maka konsumen tidak memiliki pilihan yang variatif terhadap produk motor Yamaha. 
b. Kapasitas produksi yang masih tergolong terbatas sehingga masih sering inden.

c. Jumlah bengkel resmi tidak seimbang dengan jumlah unit sepeda motor yang terjual.

d. Kurang unggul dalam pasar kelas bawah low price market

\begin{tabular}{|c|c|c|c|}
\hline Faktor faltor Internal Utama & Bobot & Peringkat & Skor \\
\hline \multicolumn{4}{|l|}{ Strenght } \\
\hline $\begin{array}{l}\text { L. Meniiliti kevaggotan dengan prodok yang memiliki alselerasi } \\
\text { yang cepat }\end{array}$ & 0,20 & 4 & 0,80 \\
\hline $\begin{array}{l}2 \text { Memilitio brand managenent yang baik melaloi brand } \\
\text { ambassador yang represantip terhadap produlonya }\end{array}$ & 0,13 & 3 & 0,39 \\
\hline $\begin{array}{l}\text { 3. Memiliki castuner dan connunity managenent melisoi promosi } \\
\text { yang intens dan intim }\end{array}$ & 0,13 & 1 & 0,13 \\
\hline \multicolumn{4}{|l|}{ Weakness } \\
\hline 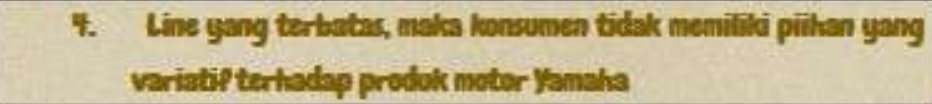 & 0,17 & 2 & 0,34 \\
\hline $\begin{array}{l}\text { 5. Kapasitas produlusi yang masih tergolong tertatas sethinggs } \\
\text { masih sering indea }\end{array}$ & 0,12 & 1 & 0,12 \\
\hline $\begin{array}{l}\text { 6. Jumlah bengleal yang resmi tidek seimbang dengan jonlah unit. } \\
\text { sepeda motor yang terjoal }\end{array}$ & 0,12 & 2 & 0,24 \\
\hline 7. Norang unggol dalam psar kelas bewah / low price martut & 0,13 & 2 & 0,26 \\
\hline TOTAL & 1,00 & & 2,28 \\
\hline
\end{tabular}

Gambar 2. Factor Internal Utama

Matrik Profil Kompetitif Perusahaan

\begin{tabular}{|c|c|c|c|c|c|c|c|}
\hline Yanahes & Honds & & & & & & \\
\hline $\begin{array}{l}\text { Falstor faktor keberhasilan } \\
\text { penting }\end{array}$ & Bobot & Peringkat & Skor & Peringlat & Skor & Peringhat & Ikor \\
\hline 1. Itan & 0,15 & 3 & 0,45 & 4 & 0,60 & 3 & 0,45 \\
\hline 2. Vwoiftus froduk & 0,20 & 4 & 0,80 & 4 & 0,80 & 2 & 0,40 \\
\hline 1. Aaga saing llarys & 0,15 & 3 & 0,45 & 3 & 0,45 & 2 & 0,30 \\
\hline 4. Mangienea & 0,10 & 1 & 0,10 & 1 & 0,10 & 1 & 0,10 \\
\hline 5. Prisi Keosngen & 0,05 & 1 & 0,05 & 2 & 0,10 & 2 & 0,10 \\
\hline 6. Loysits Konsumen & 0,15 & 3 & 0,45 & 3 & 0,45 & 3 & 0,45 \\
\hline 7. Aspansi Obotal & 0,10 & 4 & 0,40 & 3 & 0,30 & 3 & 0,30 \\
\hline 8. Panga Paser & 0,10 & 2 & 0,20 & 3 & 0,30 & 2 & 0,20 \\
\hline Total & 1,00 & & 29 & & 3,1 & & 2,3 \\
\hline
\end{tabular}

Gambar 3. Matrik Profil Kompetitif Perusahaan

Pada matriks ini perusahaan pesaing / competitor yang digunakan sebagai acuan yaitu PT Honda dan PT Suzuki, karena disini penulis melihat bahwa kedua perusahaan tersebutlah yang merupakan pesaing utama dari PT Yamaha di Indonesia. Selain itu produk - produk yang dikeluarkan dari ketiga perusahaan tersebut selalu bersaing keras. Terutama persaingan produk dengan PT Honda. Kedua perusahaan tersebut berlomba untuk mengeluarkan inovasi dalam transportasi kendaraan, misalnya saat PT Honda meluncurkan dan memperkenalkan 
sepeda motor skubek kemudian PT Yamaha mengeluarkan produk sepeda motor bebek berkapasitasbesar dikelas bawah yaitu Vega-ZR dengn kapasitas 115 cc. Produk Vega-ZR tersebut dapat membawa PT Yamaha menduduki posisi tertinggi penjualan sepeda motor di Indonesia. Sedangkan pada produk PT Honda motor skubek justru kurang diminati di pangsa pasar sehingga rating PT Honda pun merosot dan diduduki oleh PT Yamaha. Sedangkan persaingan dengan PT Suzuki sendiri PT Yamaha bersaing dari segi harga. Keduanya sama sama berusahan mengeluarkan produk dengan harga yang ekonomis untuk kalangan kelas bawah.

Matrik SWOT terdiri dari 9 kolom, sebagai berikut :

Tabel 1.

Matrik SWOT

\begin{tabular}{|c|c|c|}
\hline \begin{tabular}{l}
\multicolumn{1}{c}{ STRENGTH } \\
1. Memiliki brand management \\
yang baik melalui brand \\
ambassador yang \\
representative terhadap \\
produknya \\
2. Memiliki consummer dan \\
community management \\
melalui promosi yang intens \\
dan intim. \\
3. Menjalani strategi vertical \\
integration operasi buatan \\
suku cadang, perakitan motor \\
dan pemasaran di Indonesia.
\end{tabular} & $\begin{array}{l}\text { WEAKNESS } \\
\text { 1. Product line yang terbatas, } \\
\text { maka konsumen tak memiliki } \\
\text { pilihan yang variatif terdapat } \\
\text { produk motor Yamaha. } \\
\text { 2. Kapasitas produksi yang } \\
\text { masih tergolong terbatas } \\
\text { sehingga masih sering inden. } \\
\text { 3. Jumlah bengkel resmi tidak } \\
\text { seimbang dengan jumlah unit } \\
\text { sepeda motor yang terjual. } \\
\text { 4. Kurang unggul dalam pasar } \\
\text { kelas bawah low price } \\
\text { market. }\end{array}$ & \\
\hline $\begin{array}{l}\text { OPPORTUNITY : } \\
\text { 1. Perubahan gaya hidup } \\
\text { konsumen. Motor matik } \\
\text { menjadi market leader dan } \\
\text { trend setter (market driven). } \\
\text { 2. Perubahan teknologi. } \\
\text { 3. Populasi penduduk terbesar } \\
\text { ketiga di Asia. } \\
\text { 4. Kenaikan tingkat permintaan } \\
\text { kendaraan motor beroda dua. } \\
\text { 5. Kenaikan tingkat kemacetan } \\
\text { lalu lintas di kota-kota besar }\end{array}$ & \begin{tabular}{l}
\multicolumn{1}{c}{$\mathbf{S} \mathbf{O}$} \\
S1.O4 Memperbaiki brand \\
management Yamaha melalui \\
brand ambassadornya. Misalnya \\
dengan menjadikan artist yang \\
sedang boming sekarang ini agar \\
permintaan produknya semakin \\
meningkat. \\
S3.O3 Menambah pabrik \\
pembuatan suku cadang, \\
perakitan motor dan \\
pemasarannya di setiap wilayah \\
di Indonesia karna permintaan \\
masyarakat akan produk \\
kendaraan beroda dua selalu \\
meningkat.
\end{tabular} & \begin{tabular}{|l}
\multicolumn{1}{c|}{ W } \\
W1.O1 \\
Melihat perubahan \\
gaya hidup masyarakat \\
yang selalu berubah- \\
ubah. \\
Yamaha harus bisa \\
menciptakan produk- \\
produk yang lebih \\
bervariatif \\
sesuai dengan gaya \\
hidup masyarakat. \\
W4.O3 \\
Menciptakan produk \\
yang lebih menekankan \\
pada kelas bawah (low \\
price market) karena \\
melihat penduduk \\
Indonesia mayoritas \\
masyarakat kalangan \\
menengah ke bawah.
\end{tabular} \\
\hline
\end{tabular}




\section{THREAT}

1. Keterbatasan minyak bahan bakar Indonesia dan dunia.

2. Persaingan pasar sepeda motor nasional.

3. Maraknya produk motor asal Cina yang masuk ke Indonesia.

4. Kebijakan pemerintah mengenai pembatasan BBM bersubsidi (premium).

5. Kebijakan pemerintah terhadap pengurangan jumlah penghasil produk serupa. kendaraan roda dua mengurangi lalu lintas meski masih sekedar wacana). \begin{tabular}{c|cc}
$\mathbf{S}$ & $\mathbf{T}$ & $\mathbf{W}$ \\
& & \\
33.T1 Menciptakan produk yang & W4.T3 Seperti produk
\end{tabular} lebih irit bahan bakar karna China yang mematok keterbatasan minyak bahan bakarharga terjangkau serta di Indonesia dan Dunia. memiliki desain yang menarik setiap

S2.T2 Melakukan promosi yang produknya, lebih inten dan intim misalnya Yamaha juga dapat dengan cara memberikan memproduksi sepeda potongan harga (discount) pada motor dengan harga produk tertentu agar tetap dapat terjangkau dengan bersaing dengan perusahaan desain yang menarik pula agar menarik perhatian kosumen.

W1.T5 Yamaha sebaiknya menciptakan inovasi baru dengan memproduksi alat transportasi lain selain kendaraan roda dua, misalnya sepeda. Hal tersebut dilakukan agar sesuai dengan kebijakan pemerintah Indonesia yang akan melakukan pengurangan jumlah kendaraan roda dua untuk meminimalisir adanya kemacetan lalu lintas.

\section{BCG Matrik}

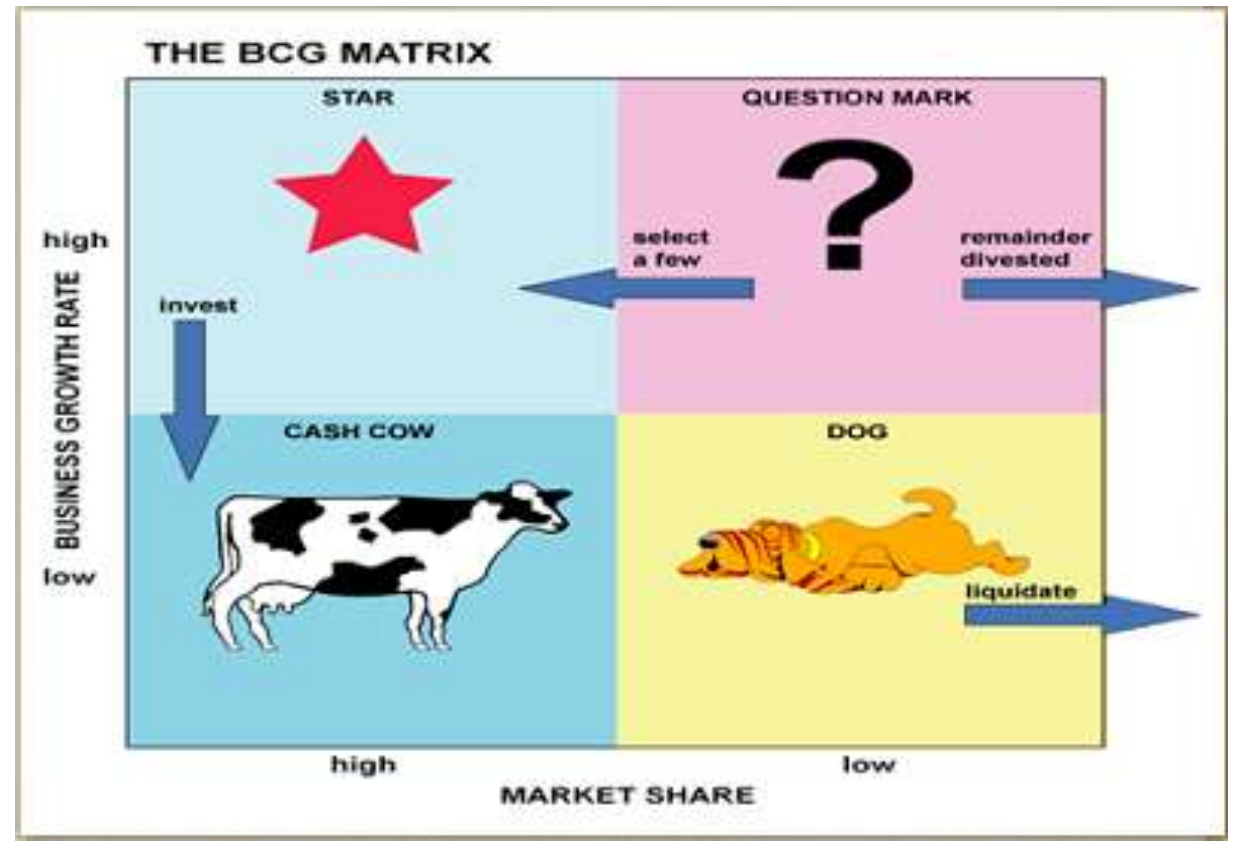

Gambar 4. The BCG Matrik 
1. Question Marks

Question mark adalah produk di pasar berkembang, tetapi memiliki pangsa pasar yang rendah. Pada dasarnya didominasi dengan produk-produk baru, dimana pembeli belum menemukan atau jarang menemukan produk-produk baru tersebut. Produk-produk pada posisi ini perlu meningkatkan pangsa pasar dengan cepat atau produk-produk ini akan berpindah pada posisi dogs. Produk Yamaha yang menduduki posisi ini adalah Yamaha N-Max.

2. Stars

Stars adalah yang memiliki pangsa pasar tinggi di pasar yang berkembang.Stars merupakan pemimpin dalam unit bisnis namun masih perlu banyak dukungan untuk promosi dan penempatan. Apabila pangsa pasar dijaga, stars akan cenderung tumbuh menjadi Cash Cow. Produk Yamaha yang menduduki posisi ini adalah Yamaha Mio.

3. Cash Cow

Cash cow adalah produk yang berada pada posisi pangsa pasar tinggi di pasar yang dewasa (mature market). Apabila keunggulan kompetitif telah dicapai, cash cow memiliki margin keuntungan yang tinggi dan menghasilkan banyak aliran kas. Cash cow adalah produk-produk yang diperjuangkan oleh perusahaan. Produk Yamaha yang menduduki posisi ini adalah Yamaha Mio.

4. Dogs

Dogs adalah produk yang berada pada posisi pangsa pasar rendah di pasar yang pertumbuhannya rendah. Kondisi semacam ini harus dihindari dan diminimalisasi.Produk Yamaha yang menduduki posisi ini adalah Yamaha Nouvo.

\section{Rekomendasi Strategi Spesifik dan Tujuan Jangka panjang}

Pada umumnya strategi spesifik dan tujuan jangka panjang menggambarkan mengenai strategi yang di tempuh serta tujuan besar yang ingin dicapai oleh perusahaan.

\section{Rekomendasi tujuan tahunan berikut kebijakan 1 tahun kedepan}

Tujuan tahunan yang penulis rekomendasikan untuk PT YAMAHA yaitu :

1. Menciptakan proyek inovasi (Inovation Project ). Caranya adalah melahirkan produk yang lebih stylist dengan beberapa modifikasi dari produk yang sudah ada. Dengan cara meningkatkan kinerja kendaraan, kehandalan, dan nilai estetik. Selain bisa berinovasi dengan produk lama (memperbaiki mutu produk), Yamaha juga dapat melakukan inovasi pada produk baru. Dalam hal ini, Yamaha dituntut untuk berani tampil beda.

2. Meningkatkan kualitas pelayanan konsumen (Exellent Service). Pelayanan prima yang dimaksud adalah pelayanan ( service ) Yamaha yang berorientasi pada kepuasan pelanggan.

\section{Rekomendasi tahapan untuk review dan evaluasi strategi}

Tahapan review dan evaluasi strategi yaitu dengan merangsang sikap kritis terhadap ekspetasi dan asumsi yang ada bagi para karyawan terutama manager serta memunculkan sikap kreativitas untuk menghasilkan alternative dan merumuskan criteria evaluasi guna meningkatkan laba dan penjualan perusahaan. Selain itu, perusahaan perlu mencermati serangkaian trend, termasuk trend individu dan kebanyakan yang merupakan hasil interkasi 
antar tren. Perbandingan pun perlu dilakukan, yaitu perbandingan kinerja dari waktu ke waktu, perbandingan kinerja dengan kinerja pesaing dan perbandingan kinerja dengan ratarata industri.

\section{KESIMPULAN DAN SARAN}

\section{Kesimpulan}

Managemen strategis yang diterapkan secara rigid dan kaku terhadap suatu perusahaan pasti tidak akan mampu bertahan terhadap perubahan eksternal maupun internal perusahaan. Perencanaan strategis yang terlalu kaku menimbulkan kesulitan jika perubahan lingkungan terjadi dengan tiba-tiba. Untuk itulah dibutuhkan pendekatan tata kelola yang mampu beradaptasi dengan lingkungan.

Pada PT YAMAHA strategi yang digunakan sudah cukup baik yakni dengan memanfaatkan peluang yang ada dan mengoptimalkan kekuatan yang sudah terbentuk, selain itu dengan melakukan inovasi inovasi produk kebertahanan produk Yamaha di pangsa pasar.Kesesuaian antara strategi dan visi misi pun sudah dilakukan sehingga langkah yang ditempuh pun jelas.Jadi secara keseluruhan managemen strategi PT YAMAHA sudah dapat dikatakan baik.

\section{Saran}

PT YAMAHA sebagai perusahaan yang telah lama berdiri yang di kenal produk produknya yang memiliki kualitas yang tidak diragukan lagi diharapkan kedepannya dapat meningkatkan managemen strategi yang telah digunakan, serta dapat menciptakan produk yang lebih dari saat ini.

\section{DAFTAR RUJUKAN}

Adityas,https://digilib.uns.ac.id/dokumen/download/12702/MjcyNjI=/Kajian-terhadapstrength- weakness-opportunities-threats-kontraktor-dalam-industri-jasa-konstruksiSub-bidang-bangunan- gedung-dan-perumahan-studi-kasus-pada-kontraktorgolongan-kecil-di-Surakarta-Study-of-strength- weakness-opprtunities-threats-ofabstrak.pdf.

Ahmad Fauzi, Hapzi. https://www.academi.edu/39791655/8 AhmadFauzi Hapzi Ali SWOT Analisis PT Pertamina UMB 2019 (06 Oktober 2019, 20.10)

Bela, 2015. http://belaputraperdana.blogspot.com/2015/05/analisis-swot-perusahaankontraktor.html

Sufieariyanti, 2016. http://sufieariyanti.blogspot.com/2016/11/manajemen-strategik-analisisefe-ife.html (01 Oktober 2019, 22.20)

Langitbiru, 2016. http://siukhtilangitbiru.blogspot.com/2016/01/analisis-manajemenstrategik- pt-yamaha.html

Hany, S dkk. 2016. Analisis Strategi Pemasaran Menggunakan Matriks SWOT dan QSPM (Studi Kasus: Restoran WS Soekarno Hatta Malang). Jurnal Teknologi dan Manajemen Agroindustri. Vol. 1, No.5, Hal. 46-53

Rangkuti, Freddy. 2001.Analisis SWOT : Teknik Membedah Kasus Bisnis. Penerbit PT Gramedia Pustaka Utama: Jakarta 